\title{
Estudo da composição florística do banco de sementes em área de caatinga em processo de recuperação
}

\author{
Study of the floristic composition of the seed bank in a caatinga area in the process of recovery
}

Estudio de la composición florística del banco de semillas en zona de caatinga en proceso de recuperación

Marcelo Pereira Dutra Júnior

ORCID: https://orcid.org/0000-0002-3460-0579 Universidade Federal Rural de Pernambuco, Brasil E-mail: marcelo16.ef@gmail.com

Ivonete Alves Bakke

ORCID: https://orcid.org/0000-0002-6015-6977 Universidade Federal de Campina Grande, Brasil E-mail: ivobakke@gmail.com

Everton Monteiro da Costa

ORCID: https://orcid.org/0000-0003-1965-2386 Universidade Federal de Campina Grande, Brasil E-mail: evertonmonteiroeng@gmail.com

Sebastiana Renata Vilela Azevedo ORCID: https://orcid.org/0000-0001-8927-4996 Universidade Federal Rural de Pernambuco, Brasil E-mail: renatavilela77@gmail.com

Iara Cristina Araújo Rocha ORCID: https://orcid.org/0000-0002-7874-9447 Universidade Federal Rural de Pernambuco, Brasil E-mail: iaracristinarocha7@gmail.com

Emanuel Messias Pereira Fernando ORCID: https://orcid.org/0000-0003-3350-868X Universidade Federal de Campina Grande, Brasil E-mail: messias21@gmail.com

\begin{abstract}
Resumo
O bioma Caatinga é predominantemente formado por espécies arbustivo-árboreas, sendo utilizadas pelo homem, na alimentação de animais, além de fornecerem sementes para o processo de regeneração natural. Este estudo identificou a composição florística no banco de sementes de uma área de caatinga em processo de recuperação localizada na Fazenda Nupeárido, Patos-PB, Brasil. Em setembro de 2016, foram coletadas cinquenta amostras de solo mais serapilheira e levadas ao Viveiro Florestal do CSTR/UFCG. Estas amostras foram irrigadas diariamente por um ano para a quantificação e identificação da composição florística do seu banco de sementes. A diversidade e abundância das espécies foram estimadas utilizando-se os índices de Shannon-Wiener (H') e de equabilidade de Pielou (e'). O banco de sementes apresentou em sua maioria espécies herbáceas, com destaque para as famílias Poaceae e Convolvulaceae. A orientação Oeste apresentou maior diversidade de espécies $\left(H^{\prime}=2,69\right)$ e distribuição mais uniforme $\left(\mathrm{e}^{\prime}=0,47\right)$.
\end{abstract}

Palavras-chave: Área degradada; Flora herbácea; Regeneração natural.

\begin{abstract}
The Caatinga biome is predominantly formed by shruby-tree species, used by humans to feed animals, in addition to providing seeds for the natural regeneration process. This study identified the floristic composition in the seed bank of a caatinga area in recovery process located at Nupeárido Farm, Patos-PB, Brazil. In September 2016, fifty soil \& litter samples were collected and taken to the CSTR/UFCG Forest Nursery facilities. These samples were irrigated daily for one year to quantify and identify the floristic composition of the seed bank. Species diversity and abundance were estimated using the Shannon-Wiener (H') diversity and Pielou (e') equitability indices. especially from the Poaceae and Convolvulaceae families. The West orientation showed greater species diversity $\left(\mathrm{H}^{\prime}=2.69\right)$ and more uniform distribution $\left(\mathrm{e}^{\prime}=0.47\right)$.
\end{abstract}

Keywords: Degraded area; Herbaceous flora; Natural regeneration. 


\section{Resumen}

El bioma de Caatinga está formado predominantemente por especies de árboles arbustivos, siendo utilizados por los humanos para alimentar a los animales, además de proporcionar semillas para el proceso de regeneración natural. Este estudio identificó la composición florística en el banco de semillas de un área de caatinga en proceso de recuperación ubicada en Fazenda Nupeárido, Patos-PB, Brasil. En septiembre de 2016, se recolectaron cincuenta muestras de suelo más basura y se llevaron al vivero forestal CSTR / UFCG. Estas muestras fueron regadas diariamente durante un año para cuantificación e identificación de la composición florística de su banco de semillas. La diversidad y abundancia de especies se estimaron utilizando los índices de uniformidad de Shannon-Wiener (H') y Pielou (e'). El banco de semillas tenía principalmente especies herbáceas, con énfasis en las familias Poaceae y Convolvulaceae. La orientación oeste mostró una mayor diversidad de especies $\left(\mathrm{H}^{\prime}=2.69\right)$ y una distribución más uniforme $\left(\mathrm{e}^{\prime}=0.47\right)$.

Palabras clave: Área degradada; Flora herbácea; Regeneración natural.

\section{Introdução}

A Caatinga é uma vegetação tropical seca predominante na região semiárida do Brasil, abrange aproximadamente $900.000 \mathrm{~km}^{2}$ de extensão territorial, representando mais da metade da região Nordeste (Almeida, 2018). O semiárido brasileiro apresenta uma grande irregularidade de chuvas ao decorrer dos últimos anos, ocasionando longos períodos de estiagem, sendo este um dos fatores responsáveis pelo baixo desenvolvimento das espécies florestais na região. Além disso, a má distribuição da precipitação associada também às altas taxas de evapotranspiração têm impossibilitado a decorrência dos processos ecológicos no ambiente, como a chuva de sementes e a regeneração natural, não atuando assim, de maneira tão eficiente (Oliveira et al., 2013).

A vegetação da Caatinga é constituída por espécies xerófilas adaptadas ao clima quente e seco. Muitas apresentam caducifólia (queda das folhas), microfilia (folhas pequenas), abundância de espinhos e órgãos armazenadores de água e nutrientes. Estas adaptações proporcionam a sobrevivência das plantas em ambientes considerados hostis para a maioria das espécies, possibilitando o surgimento de grande quantidade de fitomassa (Araújo et al., 2010). Além disso, a região é responsável por apresentar fitofisionomia e florística variada com espécies herbáceas, lenhosas, cactáceas e bromeliáceas (Alves et al., 2017).

De acordo com Teixeira et al. (2017), o processo de exploração dos recursos florestais no semiárido nordestino tem sido intensificada de forma a prejudicar o desenvolvimento de espécies, ocasionando em mudanças do bioma. Para Barbosa (2017), a degradação em uma área ocasiona uma grande perda e diminuição de diversos recursos ambientais, tais como, a impossibilidade de produção de alimentos, produtos madeireiros, além da redução da biodiversidade.

Uma maneira de recuperar uma área é por meio do banco de sementes do solo, que é uma estrutura composta por sementes viáveis, presentes na superfície do solo, na serapilheira ou nas camadas mais interiores do componente edáfico. Permite ainda, determinar a composição do estrato florestal, bem como a flora residente (Lucena et al., 2016). O mesmo pode ser considerado um ótimo indicador ecológico para avaliação de ambientes degradados, pois através deste é possível analisar o potencial de autorregeneração de uma área (Sousa et al., 2020). No entanto, um outro fator que pode interferir diretamente o processo é o nível de degradação do ambiente, que em condições muito adversas afeta o solo e sua estrutura, tornando a regeneração da floresta mais lenta (Lemos Filho et al., 2017).

Por outro lado, com o banco de sementes do solo é possível observar as espécies que podem se desenvolverem e garantir a composição florística local. Portanto, conhecer esse procedimento é essencial, pois irá permitir a realização de um manejo adequado e aumentar as chances de conservação e recuperação da caatinga (Lucena, Alves e Bakke, 2017). Contudo, este trabalho teve como objetivo identificar a composição florística do banco de sementes em área de Caatinga em processo de recuperação. 


\section{Metodologia}

O estudo foi realizado em uma área degradada que se encontra em processo de recuperação desde 2005 situada na fazenda NUPEARIDO (Núcleo de Pesquisa para o semiárido), pertencente à Universidade Federal de Campina Grande (UFCG), do Centro de Saúde e Tecnologia Rural (CSTR), Campus de Patos, Paraíba, sob as coordenadas geográficas $07^{\circ} 05^{\prime} 10^{\prime}$ ' sul e $37^{\circ} 15^{\prime} 43^{\prime \prime}$ oeste (Figura 1 ).

Figura 1. Localização geográfica da área experimental na Fazenda NUPEÁRIDO, Patos, Paraíba.



Fonte: Autores.

O clima da região é classificada como BS'h, quente e seco, com temperaturas elevadas, (Alvares et al., 2014), e pluviosidade variável a cada ano, geralmente apresenta média anual inferior a $800 \mathrm{~mm}$, com presença de chuvas irregulares concentradas nos primeiros meses do ano (PERH-PB, 2006).

$\mathrm{Na}$ área, foram plantadas em 2008 as espécies pioneiras arbóreas, Mimosa tenuiflora (Willd. Poir.) e Cnidoscolus quercifolius (Pohl), que se encontram em fase adulta. Em março de 2014, foram plantadas as espécies secundárias Amburana cearensis (Allemão A. C. Sm.) e Handroanthus impetiginosus (Mart. Ex DC. Mattos), as quais se encontram na fase juvenil.

Em agosto de 2016 foram coletadas cinquenta (50) amostras de solo + serapilhera, com o auxílio de uma moldura de ferro com $30 \mathrm{~cm}$ x $50 \mathrm{~cm}$ x $3 \mathrm{~cm}$, dispostas aleatoriamente em toda a área. A coleta ocorreu seguindo as quatro orientações (Norte, Leste, Oeste e Sul) de cada parcela.

O material coletado foi acondicionado em bandejas de plástico $(33 \mathrm{~cm}$ x $24 \mathrm{~cm}$ x $5 \mathrm{~cm})$ identificadas e perfuradas para drenar o excesso de água e dispostas em bancadas de alvenaria em ambiente telado com fator de redução solar de $50 \%$ do Viveiro Florestal. As bandejas foram irrigadas manualmente uma ou duas vezes ao dia dependendo da necessidade de mantêlas úmidas para garantir condição adequada à germinação das sementes

O acompanhamento da germinação realizou-se diariamente através de registros fotográficos e à medida que surgiam inflorescências estas eram coletadas e levadas ao Herbário do CSTR/UFCG, onde foram identificadas de acordo com a família, o nome popular/vulgar, o nome científico e modo de vida (herbáceo, arbustivo e arbóreo).

Para a análise da composição florística da área foi empregado o método de distribuição para cada espécie dentro de suas respectivas famílias, de acordo com o sistema de classificação do Angiosperm Philogeny Group III (APG III, 2009). E 
quanto à diversidade florística das espécies, optou-se pela avaliação pelo Índice de Shannon-Wiener (H’) (Equação 1) e a distribuição dos indivíduos entre as espécies nas áreas pelo Índice de Uniformidade de Pielou (e’) (Equação 2), obtido pelas equações descritas abaixo (Mata Nativa 2, 2008).

$$
H^{T}=\frac{\left[\operatorname{Non}(N)-2_{N=1}^{n} m_{n_{L}} \ln \left(m_{2}\right)\right.}{N}
$$

Em que: H' = Índice de Shannon-Wiener; $\mathrm{N}=$ número total de indivíduos amostrados; Ln = logaritmo na base neperiano; $\mathrm{S}=$ número total de espécies amostradas; $\mathrm{ni}=$ número de indivíduos amostrados da i-ésima espécie.

$$
e^{f}=\frac{H^{r}}{H_{\max }^{r}}
$$

Em que: e' = índice de Uniformidade de Pielou; H' = Índice de Shannon-Wiener e H'max = valor máximo de Shannon $\left(\mathrm{H}^{\prime}\right)=\operatorname{Ln} \mathrm{S}$.

\section{Resultados e Discussão}

A composição florística das cinquenta amostras de solo + serapilheira da área de Caatinga em processo de recuperação foi representada por 1485 indivíduos distribuídos em 14 famílias, 28 gêneros e 33 espécies (Tabela 1). As famílias que apresentaram maior riqueza foram Poaceae e Convolvulaceae com seis e cinco espécies, respectivamente. Em relação ao número de indivíduos, a família Fabaceae deteve os maiores valores com 408 indivíduos, seguida por Convolvulaceae com 378 indivíduos e Molluginaceae com 153 indivíduos. Os gêneros mais frequentes no banco de sementes foram Sthylosanthes, Evolvulus, Mollugo e Cyperus.

Tabela 1. Lista de famílias, espécies, indivíduos/orientações, total de indivíduos, nome popular e hábito de crescimento do

\begin{tabular}{|c|c|c|c|c|c|c|c|}
\hline \multirow{2}{*}{ Família / Espécie } & \multicolumn{4}{|c|}{ Indivíduos/Orientações } & \multirow{2}{*}{$\begin{array}{l}\text { Total de } \\
\text { Ind. }\end{array}$} & \multirow{2}{*}{$\begin{array}{c}\text { Nome } \\
\text { Popular }\end{array}$} & \multirow{2}{*}{$\begin{array}{c}\text { Hábito de } \\
\text { Crescimento }\end{array}$} \\
\hline & $\mathbf{N}$ & $\mathbf{S}$ & $\mathbf{L}$ & $\mathbf{O}$ & & & \\
\hline \multicolumn{8}{|l|}{ AMARANTHACEAE } \\
\hline Amaranthus sp. & 0 & 0 & 0 & 1 & 1 & Bredo & Herbácea \\
\hline CONVOLVULACEAE & & & & & & & \\
\hline Ipomea longeramosa Choisy & 30 & 10 & 11 & 13 & 64 & $\begin{array}{l}\text { Jetirana- } \\
\text { amarela }\end{array}$ & Herbácea \\
\hline Ipomea gracillina (Choisy) & 0 & 2 & 0 & 4 & 6 & Jetirana & Herbácea \\
\hline Ipomea minutiflora (Mart. \& Gal.) House & 15 & 4 & 12 & 12 & 43 & Capim-meloso & Herbácea \\
\hline Jacquemontia sp. & 0 & 4 & 0 & 1 & 5 & $\begin{array}{l}\text { Ameixa- } \\
\text { cachorro }\end{array}$ & Liana \\
\hline $\begin{array}{l}\text { Evolvulus ovatus Fernald } \\
\text { COMMELIACEAE }\end{array}$ & 157 & 33 & 48 & 22 & 260 & Azulinha & Herbácea \\
\hline $\begin{array}{l}\text { Callissia filiformis } \\
\text { Galeotti) D. R. Hunt }\end{array}$ & 9 & 5 & 3 & 1 & 18 & Tostão & Herbácea \\
\hline CLEOMACEAE & & & & & & & \\
\hline Cleome lanceolata (Mart. \& Zucc.) Iltis & 7 & 3 & 9 & 14 & 33 & Muçambê & Herbácea \\
\hline $\begin{array}{l}\text { Physostemon guianense (Aubl.) Malme } \\
\text { CYPERACEAE }\end{array}$ & 0 & 0 & 0 & 1 & 1 & Agrião do mato & Herbácea \\
\hline Cyperus odoratus $L$. & 0 & 8 & 0 & 0 & 8 & $\begin{array}{l}\text { Capim-de- } \\
\text { cheiro }\end{array}$ & Herbácea \\
\hline $\begin{array}{l}\text { Cyperus esculentus L. } \\
\text { EUPHORBIACEAE }\end{array}$ & 7 & 24 & 36 & 50 & 117 & Tiririca & Herbácea \\
\hline Euphorbia hirta L. & 0 & 0 & 1 & 4 & 5 & Erva andorinha & Herbácea \\
\hline
\end{tabular}
banco de sementes das 50 amostras de solo+serapilheira pertencente à área experimental do NUPEÁRIDO. 


\begin{tabular}{|c|c|c|c|c|c|c|c|}
\hline \multirow{2}{*}{\multicolumn{8}{|c|}{ FABACEAE }} \\
\hline & & & & & & & \\
\hline Centrosema pascuorum Mart. Ex Benth. & 35 & 18 & 20 & 10 & 83 & Manacá & Herbácea \\
\hline Mimosa tenuiflora (Willd.) Poir. & 21 & 0 & 7 & 0 & 28 & Jurema-preta & Arbórea \\
\hline $\begin{array}{l}\text { Poincianella pyramidalis (Tul.) L. P. } \\
\text { Queiroz }\end{array}$ & 0 & 2 & 3 & 0 & 5 & Catingueira & Arbórea \\
\hline $\begin{array}{l}\text { Sthylosanthes viscosa (L.) Pers. } \\
\text { MALVACEAE }\end{array}$ & 81 & 82 & 93 & 36 & 292 & Meladinha & Herbácea \\
\hline Sida ciliaris $L$. & 3 & 3 & 6 & 9 & 21 & Bredo & Arbusto \\
\hline $\begin{array}{l}\text { Waltheria } \text { sp. } \\
\text { MOLLUGINACEAE }\end{array}$ & 1 & 0 & 3 & 4 & 8 & Malva-branca & Herbácea \\
\hline Mollugo verticilata $\mathrm{L}$. & 54 & 15 & 33 & 37 & 139 & Capim-tapete & Herbácea \\
\hline $\begin{array}{l}\text { Morfo sp. } \\
\text { NYCTAGINACEAE }\end{array}$ & 10 & 3 & 1 & 0 & 14 & - & Herbácea \\
\hline Boerhavea coccínea Mill & 8 & 4 & 1 & 5 & 18 & Pega-pinto & Erva \\
\hline $\begin{array}{l}\text { Boerhavea diffusa } \mathrm{L} \text {. } \\
\text { ONEGRACEAE }\end{array}$ & 5 & 3 & 5 & 2 & 15 & Pega-pinto & Herbácea \\
\hline $\begin{array}{l}\text { Ludwigia sp. } \\
\text { POACEAE }\end{array}$ & 2 & 0 & 0 & 0 & 2 & Cruz-de-malta & Herbácea \\
\hline Dactyloctenium aegyptium L. WILLD & 10 & 9 & 11 & 7 & 37 & $\begin{array}{l}\text { Capim-pé-de- } \\
\text { galinha }\end{array}$ & Herbácea \\
\hline Dichanthelium sp. & 0 & 0 & 0 & 3 & 3 & Barba-de-bode & Herbácea \\
\hline Eragrostis pilosa $\mathrm{L}$. & 0 & 3 & 2 & 0 & 5 & Capim-panasco & Herbácea \\
\hline Cenchrus sp. & 2 & 0 & 0 & 4 & 6 & Capim-búfalo & Herbácea \\
\hline $\begin{array}{l}\text { Brachiaria decumbens (Stapf.) cv. } \\
\text { Basilisk. }\end{array}$ & 10 & 23 & 27 & 18 & 78 & $\begin{array}{l}\text { Capim- } \\
\text { braquiária }\end{array}$ & Herbácea \\
\hline Digitaria insularis (L.) Fedde & 12 & 6 & 5 & 6 & 29 & $\begin{array}{l}\text { Capim- } \\
\text { amargoso }\end{array}$ & Herbácea \\
\hline PORTULACACEAE & & & & & & & \\
\hline Portulaca elatior Mart. & 37 & 43 & 15 & 19 & 114 & Beldroega & Erva \\
\hline $\begin{array}{l}\text { Portulaca oleracea } \mathrm{L} \text {. } \\
\text { RUBIACEAE }\end{array}$ & 10 & 1 & 10 & 0 & 21 & Beldroega & Erva \\
\hline Oldenlandia corymbosa $\mathrm{L}$. & 0 & 0 & 0 & 1 & 1 & Erva-diamante & Erva \\
\hline Diodella teres (Walter) Small & 0 & 2 & 3 & 0 & 5 & Mata-pasto & Herbácea \\
\hline
\end{tabular}

Fonte: Autores (2021).

As primeiras sementes germinaram a partir do terceiro dia pós coleta o que demonstra, apesar das condições adversas do bioma, a alta viabilidade de sementes encontradas em solos semiáridos. Além disso, Souza et al. (2021), enfatizam que a emergência de plântulas favorecidas pela irrigação nos primeiros dias do experimento é comum em áreas naturais, pois isto é comumente observado com a chegadas das primeiras chuvas no início do período chuvoso.

Valores próximos para áreas degradadas na caatinga foram observados por Santos et al. (2020), com 11 famílias e 26 gêneros e espécies, além disso, a família Poaceae também deteve a maior predominância no banco de sementes. De acordo com Oliveira, Prata e Pinto (2018), o número reduzido de famílias botânicas nestes estudos pode estar relacionado ao processo de simplificação biótica, a qual é diretamente relacionada aos fatores antrópicos e que resultam em uma alta concentração de indivíduos de um mesmo grupo florístico.

As famílias Fabaceae, Convolvulaceae e Molluginaceae apresentaram os maiores números de indivíduos no decorrer da pesquisa. Fabricante e Andrade (2007), em estudo semelhante, obtiveram as famílias Fabaceae e Euphorbiaceae como destaques, logo, em função de sua vasta representatividade em outros levantamentos as colocam como famílias preponderantes na composição do bioma Caatinga, ainda mais quando relacionarmos à flora arbustiva-arbórea.

A vegetação herbácea mostrou uma frequência maior em relação às lenhosas. Resultados semelhantes foram encontrados por Ribeiro et al. (2017), para os mesmos o comportamento do banco de sementes em áreas degradadas ou em processo de recuperação é predominantemente associado a presença de herbáceas, sendo estas as primeiras colonizadas, devido ao seu ciclo de vida sazonal e facilidade de dispersão de sementes. 
O predomínio de espécies herbáceas está diretamente associado ao seu ciclo curto de vida, aspectos como sua dispersão, crescimento e desenvolvimento são bem mais ágeis que outros hábitos de vida. O estrato herbáceo consegue desenvolver plântulas continuamente e produzir altas quantidades de sementes viáveis, as quais se estabelecem no solo e garantem a manutenção consecutiva das espécies (Pinheiro et al., 2016). Além de tudo, áreas que sofreram ou ainda sofrem um certo grau de perturbação apresentam uma tendência maior de flora herbácea, pois a medida em que o ambiente perde suas características originais torna-se mais vulnerável à chegada de espécies herbáceas, muitas delas invasoras, facilitando a sua adaptação ao local bem como sua dispersão, sendo muito comum espécies das famílias Poaceae e Cyperaceae (Araújo et al., 2004).

Mesmo estando sob a presença de espécies arbóreas, poucas sementes dessa forma de vida foram observadas no decorrer da pesquisa, com maior ênfase apenas para M. tenuiflora e em menor frequência $P$. pyiramidallis. Para Medeiros et al. (2015), a maior frequência de espécies herbáceas em relação às arbóreas, deve-se a vários fatores, como a predação de roedores, assim como herbívoros que constantemente se alimentam de sementes presentes no solo. Além disso, muitas destas sementes encontram-se no solo, mas permanecem inativas por vários meses, o que inviabiliza o processo de germinação. Por outro lado, algumas sementes de espécies herbáceas e arbustivas oferecem maior resistência às condições do semiárido, permanecendo por mais tempo no solo, tornando-se menos atrativas aos predadores, priorizando sementes mais tenras.

A M. tenuiflora é uma espécie arbustiva-arbórea pioneira da Caatinga, com ótimo sistema radicular o que a permite atuar com maior proporção em âmbitos degradados (Azevedo et al., 2012). Com sementes ortodoxas, representam a principal forma de propagação da espécie, além de grande eficiência quanto a germinação, garantindo a manutenção da espécie no ambiente (Bezerra et al., 2018; Walter, Gabira e Nogueira, 2019). Dessa maneira, sua presença no banco de sementes é praticamente certa, mesmo que sob solos degradados.

No caso da P. pyramidalis, além de pioneira arbórea, é uma espécie com ampla distribuição no semiárido brasileiro, sua dispersão é autocórica, mais precisamente classificada como explosiva (Pinto et al., 2020), permitindo às sementes chegarem em ambientes mais remotos em relação à matriz, o que evidencia a presença de sementes na área em processo de recuperação.

Apesar da presença de indivíduos adultos de C. quercifolius na área, a espécie não foi verificada no banco de sementes coletado. Por ser uma espécie autocórica explosiva, suas sementes dificilmente permanecem próximas à planta mãe, além de tudo, a ausência no banco de sementes é reflexo da atuação de fauna local (Pimenta et al., 2014). Ademais, as espécies secundárias A. cearensis e H. impetiginosus ainda em estágio juvenil, também não foram presenciadas sob a condição de semente.

Em relação à riqueza das famílias e espécies presentes na área, das 14 e 33 respectivamente, 10 famílias e 16 espécies estiveram presentes em todas as orientações (Tabela 2). Analisando a dispersão das sementes de acordo com as orientações (N, S, L e O) verifica-se que não há uma predominância de sementes em relação às mesmas, uma vez que as famílias e as espécies encontram-se distribuídas uniformemente. Este resultado foi observado também por Silva (2010), estudando a influência dos ventos sobre a dispersão das sementes de três espécies arbóreas da Caatinga. 
Tabela 2. Número de famílias, de espécies e de indivíduos encontrados no banco de sementes na área experimental do NUPEÁRIDO (Núcleo de Pesquisa do Semiárido).

\begin{tabular}{|c|c|c|c|c|}
\hline \multirow[t]{2}{*}{ Famílias/ Espécies } & \multicolumn{4}{|c|}{ Orientações } \\
\hline & $\mathbf{N}$ & $\mathbf{S}$ & $\mathbf{L}$ & $\mathbf{O}$ \\
\hline Famílias Presentes & 11 & 11 & 12 & 13 \\
\hline Famílias Presentes em todas as orientações & \multicolumn{4}{|c|}{10} \\
\hline Espécies & 22 & 22 & 24 & 25 \\
\hline Espécies Presentes em todas as orientações & \multicolumn{4}{|c|}{16} \\
\hline Indivíduos / Orientação & 533 & 309 & 363 & 292 \\
\hline Total de Indivíduos & \multicolumn{4}{|c|}{1485} \\
\hline
\end{tabular}

Fonte: Autores (2021).

Além da atuação da fauna local, a ação eólica é um outro importante aspecto a ser considerado, fator abiótico comum em ambientes semiáridos abertos, que contribui diretamente com a chegada de novos propágulos ao local. Normalmente, as sementes são leves e reduzidas facilmente transportadas para outras áreas, o que evidenciam a variação de indivíduos nas mais remotas orientações (Santos, 2017).

Um fator limitante a baixa riqueza de algumas espécies no banco de sementes é a presença de precipitação reduzida ao decorrer dos últimos anos, dificultando o processo de germinação, pois nem todas as sementes apresentam ciclo de vida semelhante (Oliveira et al., 2013). Esta situação pode ser constatada no presente estudo, uma vez que nos anos de 2015,1016 e 2017, a precipitação registrada na área de estudo foi de 499,1, 528 e 485,2 mm, respectivamente, distribuída irregularmente nos seis primeiros meses do ano.

De acordo com o índice de Shannon-Wiener verificou-se maior diversidade de espécies na área para a orientação Oeste (2,69), seguida por Leste (2,56) e Sul (2,52), apesar de apresentar o maior número de indivíduos por área (533) a orientação Norte mostrou diversidade inferior às demais. A uniformidade na distribuição das espécies foi determinada pelo índice de uniformidade Pielou (e'), cujas orientações Oeste e Sul apresentaram maior uniformidade (Tabela 3). Este resultado é corroborado pelo índice de Pielou cujos valores são 0,47 e 0,43 respectivamente.

Tabela 3. Indíce de Diversidade de Shannon-Wiener (H') e Equabilidade de Pielou ( $e$ ’) referente às espécies presentes no banco de sementes da área experimental do NUPEÁRIDO (Núcleo de Pesquisa do Semiárido), a mesma encontra-se em processo de recuperação.

\begin{tabular}{c|cccc}
\hline Índice & Norte & Sul & Leste & Oeste \\
\hline $\mathrm{H}^{\prime}$ & 2,43 & 2,52 & 2,56 & 2,69 \\
$\mathrm{e}^{\prime}$ & 0,39 & 0,44 & 0,43 & 0,47 \\
\hline
\end{tabular}

Fonte: Autores (2021).

O valor encontrado para o índice de Shannon (H') foi superior se comparado com estudo realizado por Pereira Júnior et al. (2014), no qual foi obtido índice de 2,29. Por outro lado, o índice de Equabilidade (e') encontrado foi superior ao presente trabalho. Para os mesmos, além destes valores é bastante comum que haja valores ainda menores para áreas de Caatinga, especialmente em virtude das condições climáticas da região.

Em estudo realizado por Andrade et al.(2005), observaram que a diversidade das espécies foi maior para a área que se encontrava mais conservada $\left(H^{\prime}=1,51\right)$. Para os autores o valor foi superior pelo fato desta estar conservada favorecendo o desempenho dos processos ecológicos da área.

Porém, o índice de diversidade foi inferior ao encontrado por Pegado et al. (2006), em estudo referente à composição e estrutura do estrato arbustivo-arbóreo da Caatinga no município de Monteiro-PB, avaliando os efeitos da invasão biológica de algaroba - Prosopis juliflora (Sw.) DC., onde obtiveram maior diversidade $\left(\mathrm{H}^{\prime}=2,81\right.$ e 2,31) nos ambientes cujas áreas de 
Caatinga não haviam presença de Prosopis juliflora. Para os referidos autores, a maior diversidade em áreas com ausência de algaroba ocorreu justamente pelo fato das demais áreas apresentarem a espécie, onde a mesma impediu o maior estabelecimento de espécies nativas, intercedendo a decorrência do processo regenerativo.

Apesar de serem vistas como invasoras, as espécies herbáceas desempenham papel ecológico importante no ambiente, pois preenchem estes espaços, favorecendo a sucessão secundária à espécies florestais e a proteção do solo (Ribeiro et al., 2017). Por outro lado, a ausência do estrato lenhoso pode indicar uma preocupação com a manutenção e progresso sucessional do ambiente.

\section{Considerações Finais}

O banco de sementes da área de Caatinga em processo de recuperação foi composto basicamente por sementes de espécies herbáceas, provavelmente em função de seu ciclo de vida.

A baixa presença de espécies lenhosas no banco de sementes está diretamente associada à alimentação da fauna local e fatores ecológicos e abióticos como a síndrome de dispersão e a intensidade eólica.

Houve predominância de riqueza de espécies no banco de sementes nas orientações Oeste e Leste, fator associado à ação eólica.

Para avaliações futuras sugerem-se análises e estudos voltados à recuperação de áreas degradadas visando compreender a dinâmica da área, bem como decorrem o acompanhamento do processo sucessional no ambiente. Desse modo, recomenda-se outros estudos referentes ao banco de sementes do solo, estabelecimento de indivíduos regenerantes, além de outros indicadores ecológicos.

\section{Agradecimentos}

Ao CNPq - Conselho Nacional de Desenvolvimento Científico e Tecnológico - Brasil; UFCG/CSTR - Universidade Federal de Campina Grande/ Centro de Saúde e Tecnologia Rural e Unidade Acadêmica de Engenharia Florestal.

\section{Referências}

Almeida, F. C. P. (2018). Estrutura e Regeneração Natural em Remanescente de Caatinga sob Manejo Florestal, Cuité-PB. 2018. 110f. Dissertação (Mestrado em Ciências Florestais), Universidade Federal de Campina Grande, Patos-PB. http://dspace.sti.ufcg.edu.br:8080/jspui/handle/riufcg/14161

Alvares, C. A., Stape, J. L., Sentelhas, P. C., Gonçalves, J. L. M., \& Gerd Sparovek, G. (2014). Köppen's climate classification map for Brazil. Meteorologische Zeit, 22(6), 711-728. https://doi.org/10.1127 / 0941-2948 / 2013/0507

Alves, L. L. B., Alves, A. R., Barreto, F. R. S., \& Holanda, A. C. (2017). Análise florística e estrutural de uma área de Caatinga preservada no município de Mossoró/RN. Revista Conexão Ciência e Tecnologia, 11(1), 8-15. https://doi.org/10.21439/conexoes.v11i1.1066

APG III. (2009). Anupdate of the Angiosperm Phylogeny Group classification for theorders and families of flowering plants: APG III. Botanical Journal of the Linnean Society. 161, 105-121. https://doi.org/10.1111/j.1095-8339.2009.00996.x

Andrade, L. A., Pereira, I. M., Leite, U. T., \& Barbosa, M. R. V. (2005). Análise da cobertura de duas fitosionomias de Caatinga, com diferentes históricos de uso, no município de São João do Cariri, Estado da Paraíba. Revista Cerne, Lavras, 11(3), 253-262. https://www.researchgate.net/publication/237039543_Analise_da_cobertura_de_duas_fitofisionomias_de_caatinga_com_diferentes_historicos_de_uso_no_mu nicipio_de_Sao_Joao_do_Cariri_estado_da_Paraiba

Araújo, M. M., Santos, R. V., Vital, A. F M., Araújo, J. L., \& Farias Júnior, J. A. (2010). Uso do fósforo em gramíneas e leguminosas cultivadas em Neossolo do Semi-árido. Revista ACSA - Agropecuária Científica no Semi-Árido, 6(1), 40-46. http://dx.doi.org/10.30969/acsa.v6i1.66

Araújo, M. M., Longhi, S. J., Barros, P. L C., \& Brena, D. A. (2004). Caracterização da chuva de sementes, banco de sementes do solo e banco de plântulas em floresta estacional decidual ripária, Cachoeira do Sul, RS, Brasil. Scientia Forestalis, (66), 128-141, https://doi.org/10.5902/1980509835095

Azevêdo, S. M. A., Bakke, I. A., Bakke, O. A., \& Freire, A. L. O. (2012). Crescimento de plântulas de jurema preta (Mimosa tenuiflora (Wild) Poiret) em solos de áreas degradadas da caatinga, Revista Engenharia Ambiental - Espírito Santo do Pinhal-SP, 9(3), 150-160. http://ferramentas.unipinhal.edu.br/engenhariaambiental/viewarticle.php?id=745

Barbosa, P. A. C. (2017). Qualidade física do solo submetido à prática de pousio em área sob processo de desertificação. 2017. 86f. Tese (Doutorado em Ciência e Tecnologia de Alimentos) Universidade Federal do Ceará. http://www.repositorio.ufc.br/handle/riufc/34343 
Bezerra, A. C., Barbosa, L. S., Zuza, J. F. C., \& Azevedo, C. F. (2018). Water restriction on seeds of Mimosa Tenuiflora (Willd.) Poir. Brazilian Applied Science Review, Curitiba, 2(2), 635-643. https://www.brazilianjournals.com/index.php/BASR/article/view/434

Fabricante, J. F., \& Andrade, L. A. (2007). Análise estrutural de uma remanescente de Caatinga no Seridó Paraibano. Revista Oecologia Brasiliense, 11(3), 341-349. http://dx.doi.org/10.4257/oeco.2007.1103.04

Lemos Filho, L. C. A, Ferreira, L. L. N., \& Lyra, D. L. (2017). Variabilidade espacial de atributos do solo indicadores de degradação ambiental em microbacia hidrográfica. Revista AgroAmbiente On-line, 11(1), 11-20. http://dx.doi.org/10.18227/1982-8470ragro.v11i1.3413

Lucena, M. S., Alves, A. R., \& Bakke, I. A. (2017). Regeneração natural da vegetação arbóreo-arbustiva de Caatinga em face de duas formas de uso. Revista ACSA - Agropecuária Científica no Semiárido, 13(3), 212-222. http://dx.doi.org/10.30969/acsa.v13i3.887

Lucena, M. S., Silva, J. A, \& Alves, A. R. (2016). Regeneração natural do estrato arbustivo-arbóreo em área de Caatinga na Estação Ecológica do Seridó RN, Brasil. Revista Biotemas, 29(2), 17-31. https://doi.org/10.5007/2175-7925.2016v29n2p17

Mata Nativa 2. (2008). Sistema para análise fitossociológica e elaboração de planos de manejo de florestas nativas (Manual do Usuário). Cientec.

Medeiros, J. X., Silva, G. H., Ramos, T. M., Oliveira, R. B., \& Nóbrega, A. M. F. (2015). Composição e diversidade florística de banco de sementes em solo de área de Caatinga. Revista HOLOS, 31(8), 3-14. https://doi.org/10.15628/holos.2015.2098

Oliveira, D. G., Prata, A. P., \& Ferreira, A. (2013). Herbáceas da Caatinga: Composição florística, fitossociológica e estratégias de sobrevivência em comunidade vegetal. Revista Brasileira de Ciências Agrárias, 8(4), 623-633. https://doi.org/10.5039/agraria.v8i4a2682

Oliveira, D G., Prata, A. P., Ferreira, A., \& Pinto, A. S. (2018). Caracterização e atributos da vegetação herbácea em um fragmento de Caatinga no Estado de Sergipe, Brasil. Journal Hoehnea, 45(2), 159-172. https://doi.org/10.1590/2236-8906-70/2017

Pegado, C. M. A., Andrade, L. A., Félix, L. P., \& Pereira, I. M. (2006). Efeitos da invasão biológica de algaroba - Prosopis juliflora (Sw.) DC. sobre a composição e a estrutura do estrato arbustivo-arbóreo da caatinga no Município de Monteiro, PB, Brasil. Revista Acta Botânica Brasileira, 20(4), 887-898 https://doi.org/10.1590/S0102-33062006000400013

Pereira Júnior, L. R., Andrade, A. P., Araújo, K D., Barbosa, A. S., \& Barbosa, F. M. (2014). Espécies da Caatinga como Alternativa para o Desenvolvimento de Novos Fitofármacos. Revista Floresta e Ambiente, 21(4), 509-520. http://dx.doi.org/10.1590/2179-8087.024212

PERH-PB. Plano Estadual de Recursos Hídricos. Secretaria Estadual de Recursos Hídricos.

Pimenta, M. A. C., Arriel, E. F., Santos, D. R., Santos, Y. M., \& Lucena, E. O. (2014). Clonagem por alporquia de Cnidoscolus quercifolius Pohl. utilizando auxina natural. Revista Verde (Mossoró - RN - Brasil), 9(2), 83 - 94. https://www.gvaa.com.br/revista/index.php/RVADS/article/view/2679

Pinto, M. G. C., Souza, M. P., Azevedo, S. R. V., Souto, J. S., \& Silva, A. C. F. (2020). Biometria de sementes e frutos de Poincianella pyramidalis (Tul.) L.P. Queiroz. Revista Acta Biológica Catarinense, 7(3), 74-83. https://doi.org/10.21726/abc.v7i3.139

Pinheiro, M. A. M., Lacerda, A. V., Sousa, D. F., Barbosa, F. A., Gomes, A. C., Brito, M. S., Santos, O. F., Lima, J. M., \& Sousa, Z. R. A. (2016). Estudo da flora lenhosa do banco de sementes em uma área antropizada no cariri ocidental paraibano. Anais do Congresso Brasileiro de Gestão Ambiental e Sustentabilidade - Vol. 4: Congestas 2016. http://eventos.ecogestaobrasil.net/congestas/

Ribeiro, T. O., Bakke, I. A., Souto, P. C., Bakke, O. A., \& Lucena, D. S. L. (2017). Diversidade do banco de sementes em diferentes áreas de Caatinga manejadas no semiárido DA Paraíba, Brasil. Revista Ciência Florestal, 27(1), 203-213. https://doi.org/10.5902/1980509826459

Santos, O. F. (2017) Variabilidade espacial da chuva de sementes em área ciliar da caatinga no Semiárido Paraibano. 2017, 35f. Monografia - Universidade Federal de Campina Grande; Centro de Desenvolvimento Sustentável do Semiárido; Curso Superior de Tecnologia em Agroecologia. http://dspace.sti.ufcg.edu.br:8080/jspui/handle/riufcg/4954

Santos, A. M. S., Bruno, R. L. A., Cruz, J. O., Silva, I. F., \& Andrade, A. P. (2020). Variabilidade espacial do banco de sementes em área de Caatinga no Nordeste do Brasil. Revista Ciência Florestal, Santa Maria, 30(2), 542-555. https://doi.org/10.5902/1980509840039

Silva, J. E. R. (2010). Estudo da dispersão de sementes, banco de sementes e regeneração natural de três espécies arbóreas da Caatinga. 2010, 53f. Monografia (Graduação em Engenharia Florestal), http://www.bibliotecaflorestal.ufv.br/handle/123456789/8343

Sousa, F. Q., Souto, J. S., Leite, A. P., Holanda, A. C., Agra, P. F. M., \& Santos, L. C. (2020). Transposição do banco de sementes do solo para restauração ecológica da caatinga no Núcleo de Desertificação do Seridó. Brazilian Journal of Development, 6(7), 50120-50138. https://doi.org/10.34117/bjdv6n7-605

Souza, M. P., Alves, A. R., Bakke, I. A., Lopes, J. A., Santos, W. S., \& Fernando, E. M. P. (2021). Banco de sementes do solo de Caatinga submetida a plano de manejo florestal sustentável em Cuité-PB. Scientia Forestalis, 49(130), 3494. https://doi.org/10.18671/scifor.v49n130.09

Teixeira, N. F. F., Silva, E. V., \& Farias, J. F. (2017). Diagnóstico da degradação ambiental no município de Tejuçuoca - Ceará. Os Desafios da Geografia Física na Fronteira do Conhecimento, 1, 6741-6752. https://doi.org/10.20396/sbgfa.v1i2017.1866

Walter, L. S., Gabira, M. M., \& Nogueira, A. C. (2020). Accelerated aging test in Mimosa tenuiflora (Willd.) Poir. Seeds. Revista Forestal Mesoamericana Kurú, 17(40), 51-57. http://dx.doi.org/10.18845/rfmk.v17i40.4907 